\title{
Case Report: \\ THE ROLE OF INTRAVASCULAR ULTRASONOGRAPHY IN PATIENTS UNDERWENT PERCUTANEOUS CORONARY INTERVENTION
}

\author{
Yudi Her Oktaviono, Alisia Yuana Putri \\ Department of Cardiology and Vascular Medicine, Faculty of Medicine, Universitas Airlangga, Dr Soetomo Hospital, \\ Surabaya, Indonesia
}

\section{ABSTRACT}

\begin{abstract}
Intravascular ultrasonography (IVUS) has an important role as a complimentary diagnostic tool in percutaneous coronary intervention procedure. IVUS provides valuable information regarding coronary vessel lumen and dimension and also plaque burden and its characteristic. The main use of IVUS in PCI is to guide the choose of interventional strategies to optimize stent deployment. Since drug eluting stent (DES) has promised to decrease the incidence in stent restenosis and stent thrombosis than bare metal stent, but neither the suboptimal results nor the complication after stenting with DES is still high. Thus, optimization of stent deployment under IVUS guidance is important in cases to decrease stent failure after PCI procedure, as well as to decrease complication rate after stenting in order to decrease mortality rate caused by coronary artery disease. We present here the use of IVUS guidance in a 43 and 46 year-old man underwent PCI.
\end{abstract}

Keywords: Intravascular ultrasonography; percutaneous coronary intervention; stent deployment

\section{ABSTRAK}

Ultrasonografi intravaskular (IVUS) memiliki peran penting sebagai alat diagnostik komplementer pada prosedur intervensi koroner perkutan. IVUS memberikan informasi berharga mengenai lumen dan dimensi pembuluh koroner dan juga banyaknya plak serta karakteristiknya. Penggunaan utama IVUS dalam PCI adalah untuk memandu pemilihan strategi intervensi untuk mengoptimalkan pemasangan stent. Meskipun drug eluting stent (DES) menyatakan dapat mengurangi kejadian restenosis stent dan trombosis stent dibandingkan stent logam biasa, namun hasil yang suboptimal maupun komplikasi setelah stenting dengan DES masih tinggi. Dengan demikian, optimalisasi pemasangan stent di bawah panduan IVUS penting dalam penanganan kasus untuk mengurangi kegagalan stent setelah prosedur PCI, serta untuk mengurangi komplikasi setelah stenting agar dapat menurunkan angka kematian akibat penyakit arteri koroner. Dalam kasus ini pedoman IVUS digunakan pada pria 43 dan 46 tahun yang menjalani PCI.

Kata kunci: Ultrasonografi intravaskular; intervensi koroner perkutan; pemasangan stent

Correspondence: Yudi Her Oktaviono, Department of Cardiology and Vascular Medicine, Faculty of Medicine, Universitas Airlangga, Dr Soetomo Hospital, Surabaya, Indonesia. E-mail: yhoktaviono@yahoo.com

pISSN:2355-8393 • eISSN: 2599-056x • doi: http://dx.doi.org/10.20473/fmi.v55i4.17335

- Fol Med Indones. 2019;55:311-321 • Received 20 Apr $2017 \bullet$ Accepted 12 Oct 2017

- Open access under CC-BY-NC-SA license • Available at https://e-journal.unair.ac.id/FMI/

\section{INTRODUCTION}

Coronary heart disease (CHD) is a progressive disease caused by the process of atherosclerotic plaque formation in the coronary arteries (Boudi 2015). The incidence of CHD in the world is still quite high. In the United States alone around 14 million people are suffering from CHD to date. Although the incidence is still quite high, the mortality rate has decreased by $30 \%$ since the end of the 20th century (Boudi 2015). Similarly in Indonesia. Although the death rate due to heart disease as a whole is still quite high, the mortality rate due to $\mathrm{CHD}$ has decreased from $6.6 \%$ in 2004 to $4.1 \%$ in 2009 (Dharma et al 2012).

Until now, coronary angiography is still a gold standard in determining the severity of an intracoronary lesion and in establishing a diagnosis of CHD. However, on its course, the accuracy of coronary angiography becomes questionable. In some cases, a coronary artery feature from an angiogram looks normal. However, postmortem examination shows a diffuse lesion even in the absence of a normal arterial segment (Nissen \& Yock 2001). Misinterpretation and diagnosis such as this may be due to several factors. Coronary angiography is an 
examination that displays a cross section of a coronary artery that is filled with contrast in two dimensions. If the coronary arteries overlap each other, the process of interpreting of these images will become more difficult. The same difficulty can also occur if the taking of the projections is foreshortening, if there is considerable angulation of the coronary arteries, the presence of eccentric lesions, and if a calcification in the coronary arteries is present (Yoon \& Hur 2012).

Misinterpretation and diagnosis of coronary angiographic features certainly affect the selection process of the appropriate stent type and size and affect the optimal stenting process. Less optimal stent deployment process may cause several complications. One of such complications is in-stent restenosis (ISR) or stent thrombosis which may increase mortality rate due to CHD (Yoon \& Hur 2012).

To overcome the limitations of coronary angiography, currently intravascular ultrasonography (IVUS) is widely used. IVUS allows cross-sectional section of a coronary artery so that the morphology and characteristics of atherosclerotic plaque in an intracoronary lesion can be identified (Im et al 2015). IVUS can also be used to evaluate the outcome of stenting and determine the presence or absence of complications that arise shortly after stenting. The important role that IVUS has in pre-PCI, during PCI, and post-PCI periods is expected to increase the success rate of percutaneous coronary intervention (PCI) and improve outcomes in CHD patients so that it can further reduce mortality rate due to $\mathrm{CHD}$ (Liu et al 2009). This case report discusses the role of IVUS in patients undergoing PCI in pre-PCI, during PCI and post-PCI periods.

\section{CASE REPORT}

\section{Case 1}

A male patient, Mr. S, 43 years old, lived in Bojonegoro, came with complaints of typical chest pain that arose during activities and decreased with rest. There were no complaints of shortness of breath or palpitations. The patient had a history of hypertension, diabetes mellitus, and dyslipidemia. The patient also smoked for more than 10 years, 1 pack a day. In August 2015, the patient had a heart attack. Primary PCI was performed, and coronary angiography results showed a triple vessel disease with total occlusion in the RCA. Then the installation of DES stent was carried out proximal to the RCA.
Physical examination conducted at the time the patient was treated at Dr. Soetomo Hospital revealed that patient had complaints of chest pain that sometimes appeared. A stable vital sign was obtained: BP 110/70, pulse $60 x /$ minute regular, RR $20 x /$ minute, and axillary temperature 37 degree $\mathrm{C}$.

Examination revealed the following: a) Electrocardiography in December 2015: sinus rhythm $60 \mathrm{x} /$ minute, normal axis, inferior ischemia. b). Chest XRay in December 2015 showed: heart with mild cardiomegaly, CTR 55\%. Laboratory tests in December 2015 showed: Hb 11.9; leukocytes 7900; Plt 246,000; BUN 17; SK 1.4; SGOT 14; SGPT 17; Na 138; K 3.7; $\mathrm{Cl} \mathrm{103;} \mathrm{Non-reactive} \mathrm{HBsAg;} \mathrm{and} \mathrm{non-reactive} \mathrm{anti-}$ HCV. d). Echocardiography conducted in December 2015 showed that the valves showed no abnormalities. Heart chamber dimensions were within normal limits. LV systolic function was normal (EF by Teich $60 \%$; by Biplane 56\%). LV diastolic function showed abnormal relaxation. LV segmental analysis showed inferior hypokinetics (B-M-A) and no LVH.

The next coronary angiography was carried out in December 2015. Through transfemoral access with sheath 7F and using a JL 4.0 6F catheter, the following results were obtained: LMCA: Normal, LAD: stenosis appeared to be $80 \%$ significant at proximal and mid LAD, LCx Non dominant. Stenosis appeared to be $80 \%$ significant in osteal. LCX. RCA: Non-canulated.

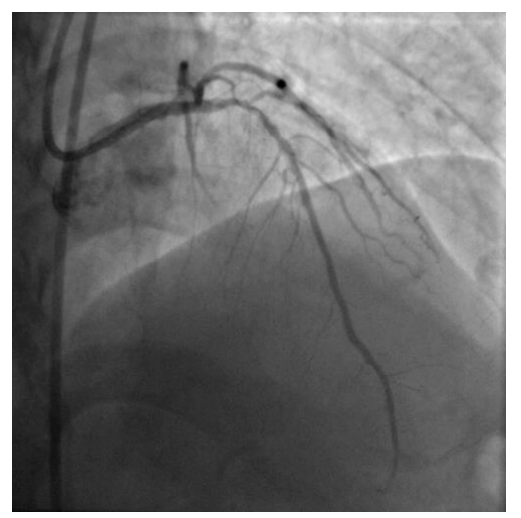

Fig. 1A. Left coronary artery angiography (LAD).

The procedure was continued with PCI started by the use of IVUS. The attempt was started by inserting GW Runthrough NS Hypercoat through GC SBS 3.5 7F towards distal LAD, trying to penetrate the lesion proximal to mid LAD. After the attempt was successful, it was continued by inserting the IVF (Opticross) 3F probe into mid-proximal LAD and the lumen crosssection of the LAD was evaluated. 


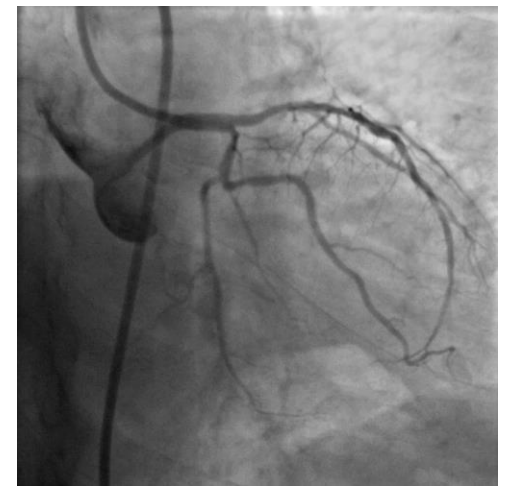

Fig. 1B. Left coronary artery angiography (LCx).

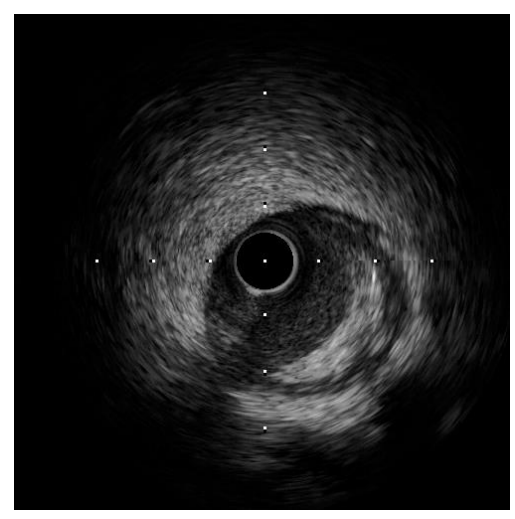

Fig. 2A. Cross-sectional image of IVUS at early LAD lesion.

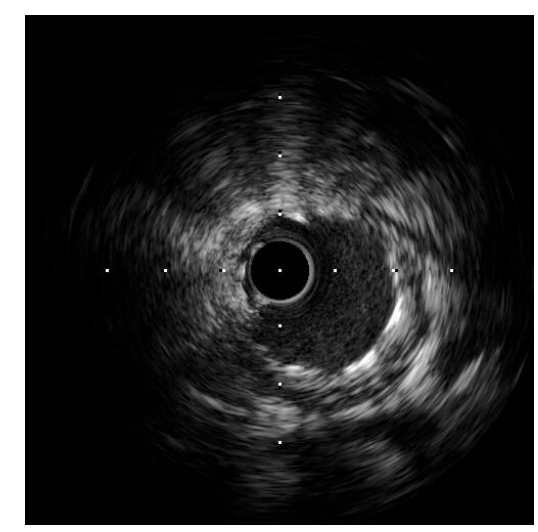

Fig. 2B. Cross-sectional image of IVUS in mid LAD lesion.

After the evaluation was complete, the IVUS probe was pulled out, a $3.5 \times 15 \mathrm{~mm}$ NC Sprinter balloon was inserted towards the mid LAD. Dilatation was done up to a pressure of $8 \mathrm{~atm}$. The balloon was stretched proximally, dilated to $12 \mathrm{~atm}$. The balloon was pulled out. The stent DES Resolute Integrity (Zotarolimus) 3.0 x $38 \mathrm{~mm}$ was inserted towards the proximal-mid LAD.
Dilatation was done up to a pressure of $14 \mathrm{~atm}$. NC Sprinter $3.5 \times 15 \mathrm{~mm}$ balloon was reinserted into mid LAD, dilated to $10 \mathrm{~atm}$. The balloon was pulled back to its proximal point, the dilatation was carried out to a pressure of $15 \mathrm{~atm}$. The procedure completed. All instruments were pulled out. The final outcome was good. During and after the procedure complications were not found.

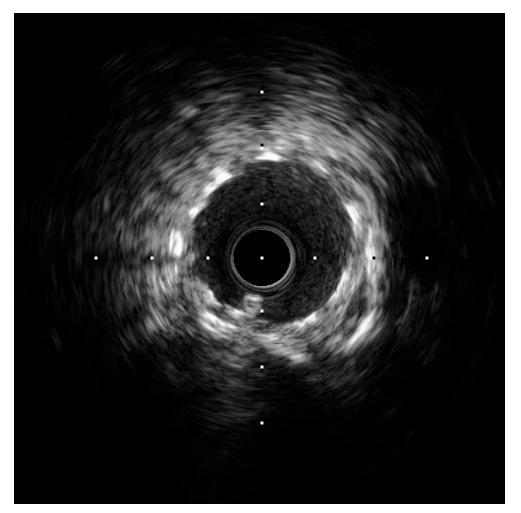

Fig. 2C. Cross sectional image of IVUS at end LAD lesion.

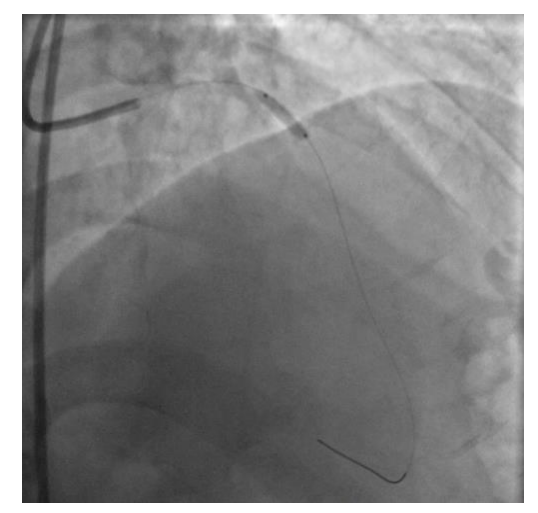

Fig. 3A. Pre-dilated LAD lesions with balloons.

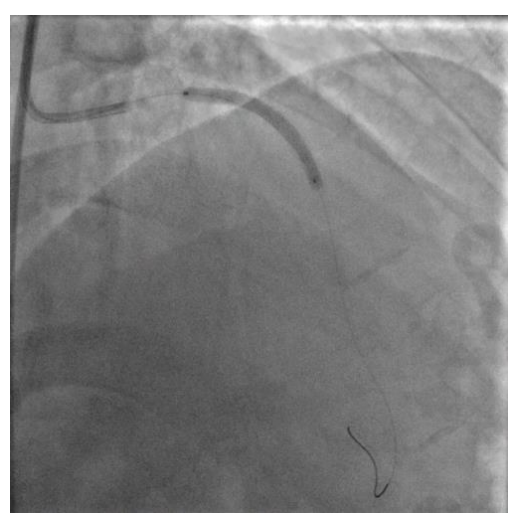

Fig. 3B. The process of stent deployment in proximalmid LAD. 


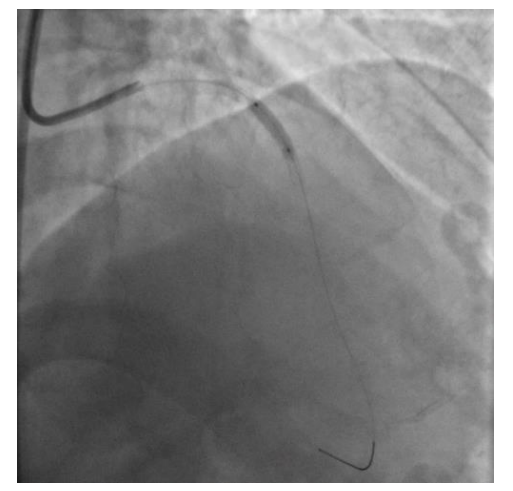

Fig. 3C. Post-dilatation with balloons.

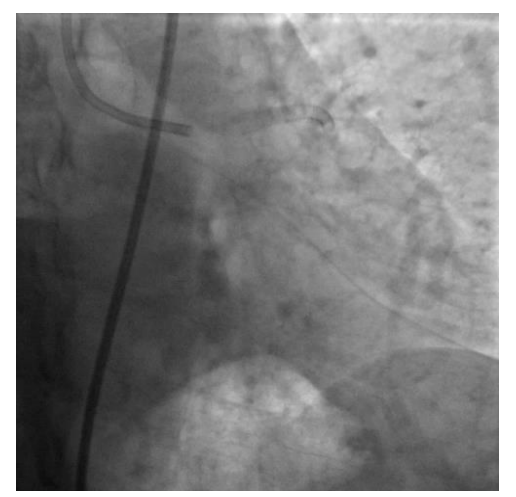

Fig. 4A. Final outcome, the stent is deployedat at proximal-mid LAD.

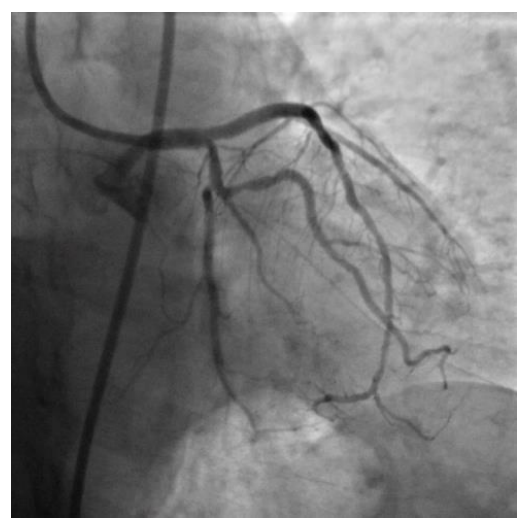

Fig. 4B. Angiography at the end of the procedure.

\section{Case 2}

A male patient, Mr. EE, 46 years old, lived in Tulungagung, came with typical chest pain, appearing intermittently during the last two years. Chest pain appeared mainly during activity, disappeared with rest and/or by administering medication under the tongue. There were no complaints of shortness of breath or palpitations. The patient denied having a history of diabetes mellitus or high blood pressure. However, the patient claimed to have high cholesterol levels and smoke for more than 20 years, 2 packs a day. In May 2015, the patient claimed to have a heart attack and was admitted to the intensive care unit (ICU) in a regional hospital for 1 week. The patient was discharged with therapies of Aspirin 1 x $100 \mathrm{mg}$, Simvastatin 0-0-20 mg, Bisoprolol 1 x $2.5 \mathrm{mg}$, and Ramipril 1 x $5 \mathrm{mg}$. In June 2015 cardiac catheterization was performed to the patient in the regional hospital. From the results of cardiac catheterization, a triple vessel disease was found and a ST stent was deployed in the RCA. The was is then advised to go to Dr. Soetomo Hospital to continue the management of stenting in LAD and LCX and to optimize the therapy.

Physical examination carried out when the patient was being treated at Dr. Soetomo Hospital revealed a patient with complaints of chest pain that only appeared during strenuous activity. Vital signs were stable: BP 130/80, regular pulse $100 \mathrm{x} /$ minute, RR 16x/minute, and axillary temperature 370C. Supporting examination showed: a). Electrocardiography in December 2015: 100x/min sinus rhythm, LAD, complete RBBB, inferior and anterior OMI. b). Chest X-Ray in December 2015: lack of inspiration, cardiomegaly impression with a CTR of $56 \%$. c). Laboratory tests in December 2015: $\mathrm{Hb}-13.5$; leukocyte 8290; platelet 374,000; BUN 14; SK 1.0; SGOT 23; SGPT 32; Na 134; K 4.2; Cl 101; Nonreactive HBsAg; and equivocal anti HCV. d). Echocardiography in December 2015 revealed mild MR valves (venous contracta $0.2 \mathrm{~cm} 2$ ). The dimension of the LV cardiac chamber were dilated (LVIDd $6.7 \mathrm{~cm}$ ) and the other segments were normal. LV systolic function decreased (EF by Teich $50 \%$; by Simpsons $41 \%$ ). The diastolic function of LV showed abnormal relaxation. RV systolic function was normal (TAPSE $2.1 \mathrm{~cm}$ ). Segmental analysis of hypokinetic LV in anteroseptal (B-M), inferoseptal (B-M), and inferior (A). There was LV concentric remodeling (LVDMI 66 $\mathrm{g} / \mathrm{m} 2$; RWT 0.62).

Coronary angiography was carried out in December 2015 through transfemoral access with sheath 7F and using GC EBU 3.5 7F catheters with the following results: LMCA Normal; LAD: There was a $40 \%$ nonsignificant stenosis in proximal LAD before SOP1 branch. Distortion of the LAD distal wall with a maximum stenosis of 50\%. LCx: Non dominant. $80 \%$ significant stenosis was seen in proximal LCx. RCA: Not cannulated. 


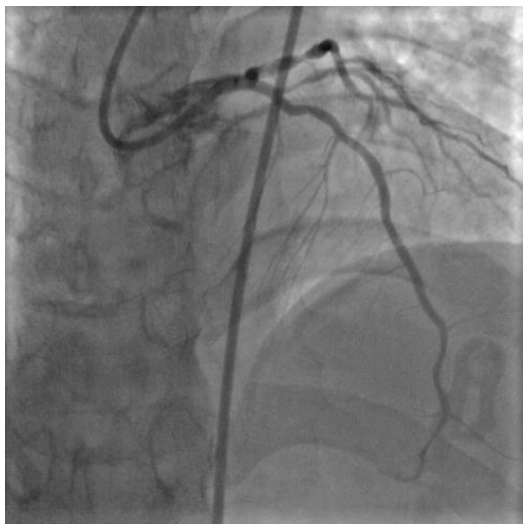

Fig. 5A. Left coronary artery angiography (LAD).

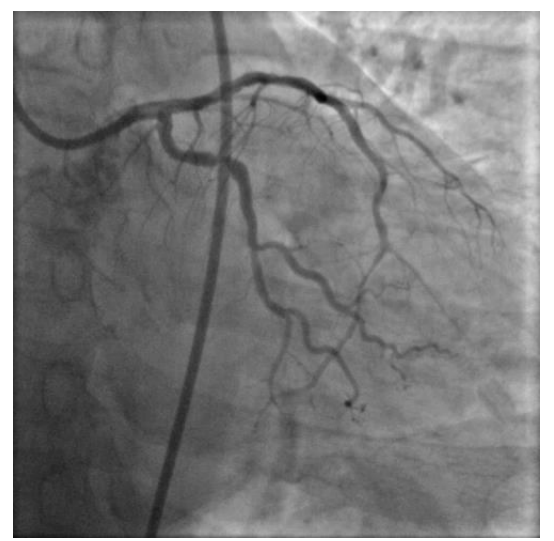

Fig. 5B. Left coronary artery angiography (LCx).

Coronary angiography was continued with PCI procedure. The PCI attempt began by inserting the GW Runthrough NS Hypercoat into the distal LCx, attempting to penetrate the lesion proximal to the LCX. The attempt was successful. Then a DES CRE-8 (Amphilimus) $3.5 \times 16 \mathrm{~mm}$ stent was inserted towards the proximal LCx. Dilatation was done up to a pressure of $14 \mathrm{~atm}$.

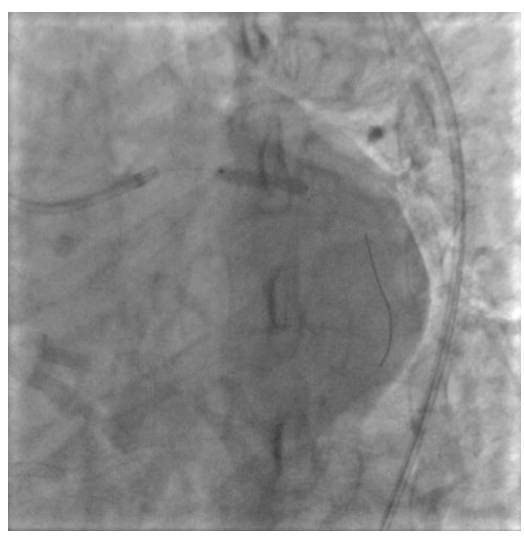

Fig. 6A. Direct stenting at LCx.

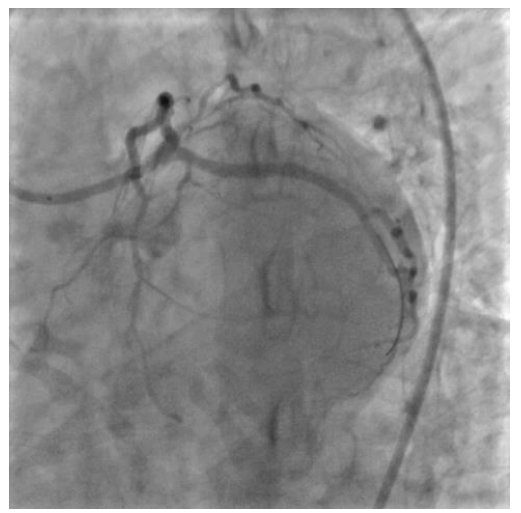

Fig. 6B. Post-direct stenting angiography in LCx.

After the stent was deployed, the IVF (Opticross) 3F probe was entered towards the distal LCx. By using IVUS, an evaluation of stent installation was performed.

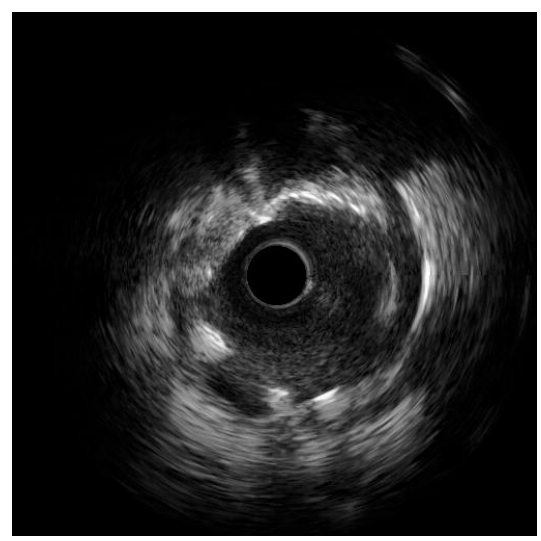

Fig. 7A. Cross-sectional image of post-stenting IVUS at early LCx lesion.

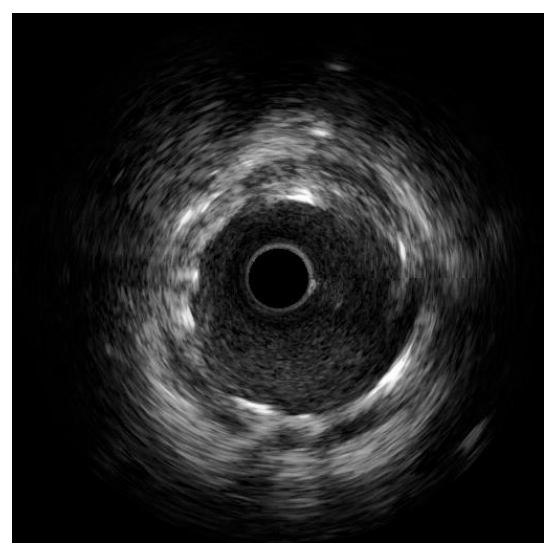

Fig. 7B. Cross-sectional image of post-stenting IVUS in mid-LCx lesion. 


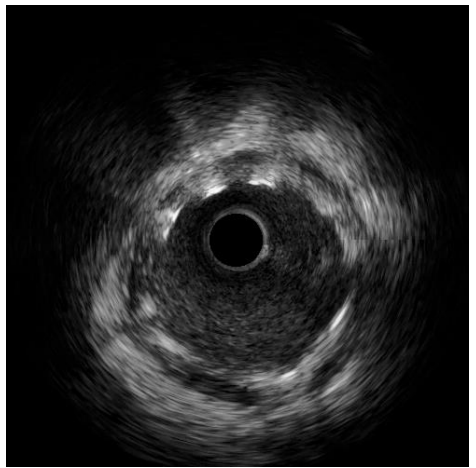

Fig. 7C. Cross-sectional image of post-stenting IVUS at the end of LCx lesion.

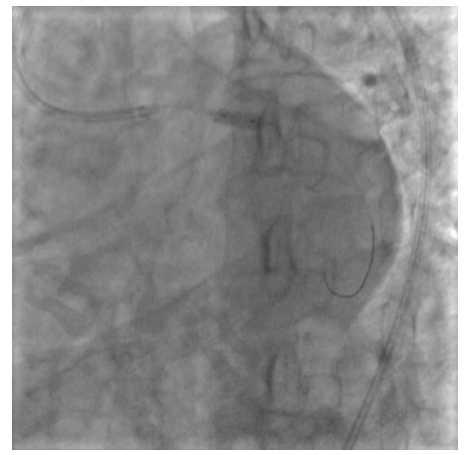

Fig. 8. Post-dilatation with the balloon.

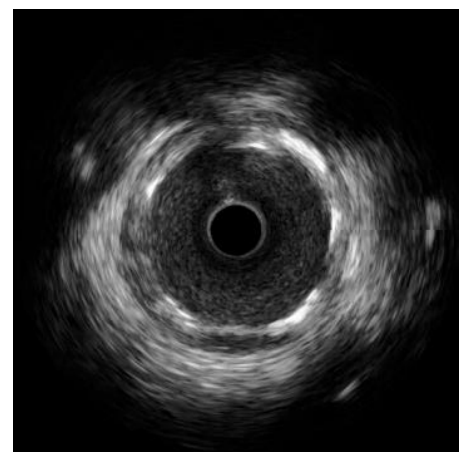

Fig. 9A. Cross-sectional image of post-dilatation IVUS stent at early LCx lesion.

After the evaluation was complete, the IVUS probe was pulled out. Then a $3.5 \times 8 \mathrm{~mm}$ NC Quantum Apex balloon was inserted towards distal LCx. The balloon was dilated to a pressure of 10 atm. The balloon was drawn proximal to LCx, dilated to $20 \mathrm{~atm}$. Then the IVF (Opticross) 3F probe was reinserted towards the distal LCx. Re-evaluation was performed post-PCI procedure. The procedure was complete. All tools were pulled out. The final outcome was good. Complications were not found during and after the procedure.

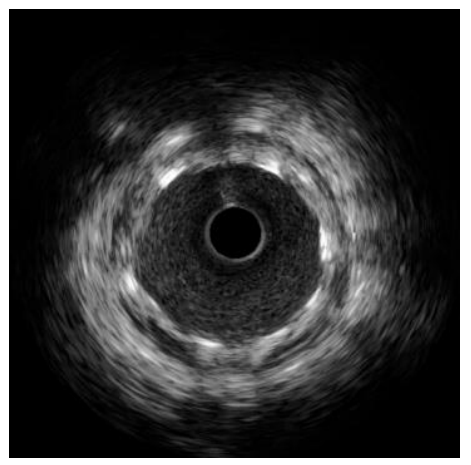

Fig. 9B. Cross-sectional image of post-dilatation IVUS stent in mid-LCx lesion.

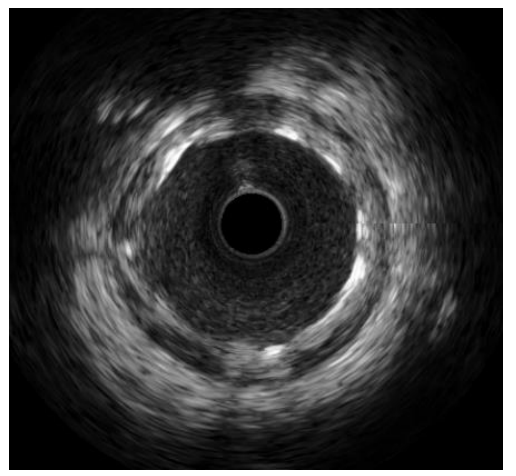

Fig. 9C. Cross-sectional image of post-dilatation IVUS stent at the end of LCx lesion.

\section{DISCUSSION}

\section{IVUS: Definition, benefits, and complications}

IVUS is one of the supporting examinations which is now widely used in conjunction with coronary angiography in PCI. By using an ultrasound probe placed at the end of the catheter, we obtain a picture of the condition of intraluminal tissue around the probe which is then reconstructed into a real-time tomographic gray-scale image resulting from the emission of ultrasound signals coming out of the probe (Lin et al 2011).

The three main components in IVUS that are needed to obtain tomographic images of a blood vessel lumen are a catheter with a small ultrasound probe at the tip of the catheter, a device for rotating both forward and backward of image capture, and a console for reconstructing a black-and-white tomographic image at one time. The catheter used is generally monorail with a size of 2.6-3.5 $\mathrm{F}$ which aims to facilitate the rapid replacement of the device and can be inserted into a $6 \mathrm{~F}$. guiding catheter. The ultrasound frequency used in 
IVUS is a high frequency which is around 20 to 50 $\mathrm{MHz}$ so that it will get a reliably good image resolution. There are two types of transducers that are often used on IVUS devices: 1). A mechanical rotating device that can rotate at a speed of $1800 \mathrm{rpm}$ so that it produces about 30 images in one second; and 2). Electronically switched multi-element array system. Although the second type of transducer is said to be easier to use, the first type has better image quality (Nissen \& Yock 2001, Lin et al 2011).

There are many advantages to using IVUS. Compared with coronary angiography, ultrasound on IVUS has the ability to penetrate tissue, so that it can directly evaluate the condition of the lumen and coronary artery walls, as well as the tissue surrounding the coronary artery walls. IVUS is also able to directly identify the condition of atherosclerotic plaque and determine the type of remodeling in the arterial wall both in segmental as well as diffuse. Therefore, IVUS is more sensitive for detecting lesions in coronary arteries in the early phase compared to coronary angiography. IVUS is also able to detect whether a plaque in the coronary artery lumen has a high risk for rupture or not, especially in plaque with insignificant stenosis on angiographic findings. Because of its ability to complement the findings of coronary angiography, IVUS is currently widely used to produce a reliable end result in PCI implementation (Nissen \& Yock 2001, Lin et al 2011). The safety of using IVUS has been widely proven. Complications that occur due to IVUS occur around 1-3\%, where the most common is temporary coronary artery spasm that can be overcome by administering nitroglycerin. Severe side effects that can occur include dissection and occlusion of the coronary arteries. These two complications rarely arise, which is only $0.5 \%$ of all cases, and almost all of them arise during the implementation of PCI (Lin et al 2011).

\section{IVUS and type of coronary artery lesions}

The use of IVUS is very useful in several types of coronary artery lesions. For example, in lesions that are intermediate on coronary angiography or complex lesions that are expected to complicate the process of stenting.

Intermediate lesions on coronary angiography (normal)

In intermediate lesions such as this, an additional examination is needed, the fractional flow reserve (FFR) which can prove whether the lesion will inhibit the process of transporting oxygen to the heart muscle (myocardial ischemia) or not. It was proved that the identification of lesions with IVUS turned out to have a correlation with the FFR results obtained (Im et al 2015, Kovarnik \& Horak 2012).

\section{Left main (LM) lesion}

Stenosis on LM is a quite important predictor of future cardiovascular events. Evaluation of coronary angiography on LM becomes quite difficult because the size of LM is quite short so it does not have the size of the reference segment and the images obtained often overlap with other branches. Jasti et al., showed that the minimum luminal area (MLA) of $<5.9 \mathrm{~cm} 2$ and the minimum diameter area (MDA) of $<2.8 \mathrm{~cm}$ correlated with the presence of a significant stenosis obtained with FFR with sensitivity and specificity of $>90 \%$. Therefore, experts in the Society of Cardiovascular Angiography and Intervention argue that IVUS can be used to assess the significance of LM stenosis with a MLA cut-off of $6 \mathrm{~mm} 2$ and to consider the need for revascularization (Im et al 2015).

\section{Non left-main (non-LM) lesion}

In contrast to LM lesions, there are many confounding factors in determining whether an intermediate lesion in non-LM will cause myocardial ischemia or not. These confounding factors include the location of the lesion, length of the lesion, eccentricity, and reference vessel diameter. Waksman et al., Showed that MLA> 3.07 $\mathrm{mm} 2$ was a cut-off to describe the absence of nonsignificant stenosis in non-LM lesions with low specificity and sensitivity rates of $64 \%$ and $65 \%$. Therefore, experts argue that IVUS cannot be used as a single examination to determine whether intermediate lesions on non-LM require revascularization or not (Im et al 2015).

\section{Complex lesions}

\section{Bifurcation lesions}

The PCI procedure in bifurcation lesions is still a fairly difficult procedure to do. The success rate is still not high enough and the final results are not yet fully satisfying. This happens because PCI in bifurcation lesion has a risk of reducing blood flow to branch arteries and the rate of restenosis is still quite high. In bifurcation lesion hemodynamic changes can also occur during PCI procedures that can affect the success of PCI. Therefore, the primary role of IVUS in bifurcation lesions is to determine precisely the characteristics of the plaque and location of the lesion, whether in the main coronary artery, carina, or ostia of the coronary arteries branch, to determine the right strategy according to the characteristics of the plaque. IVUS is also very necessary if the distribution of lesion in the bifucation 
still cannot be clearly determined (Im et al 2015, Kovarnik \& Horak 2012).

\section{Chronic Total Occlusion (CTO)}

The success of PCI procedures in CTO lesion has been associated with decreased incidence of angina, improvement in left ventricular function, and increased life expectancy in CHD patients. However, the incidence of stent thrombosis after recanalization and DES stent deployment is still quite common. This may be caused by the delayed re-endothelization process, resulting in exposure to deep plaque components, too long stent, and stent mal-apposition. IVUS can help determine whether anterograde or retrograde recanalization is needed in the CTO segment. IVUS can provide information about the location of the guidewire whether it is still in the lumen or has moved to enter the subintima. IVUS can also help find a starting location to enter the total occlusion. Overall, IVUS is recommended in patients with CTO lesions undergoing PCI procedures (Kovarnik \& Horak 2012).

\section{Long lesion}

Lesions with a quite long size will increase the likelihood of using stents that are also long. The longer the stent size, the higher the risk of stent underexpansion and malformation. These two things are known as risk factors for failure of stent deployment. In this case IVUS can be used to provide information on whether the stent with appropriate length can be installed optimally or not. Although it is hoped that the use of IVUS in long-sized lesions can reduce the number of stent failure, this is not supported by strong data. A randomized controlled trial revealed that the use of IVUS in patients with stents $>28 \mathrm{~mm}$ in size when PCI did not increase or improve the clinical outcome (cardiovascular mortality in the first year, myocardial infarction, and stent thrombosis) (Im et al 2015) .

\section{Calcified lesion}

The more severe the degree of calcification of a lesion, the higher the risk of mal-aposition of the stent and underexpansion stent. In severe calcified lesions, IVUS can be used to determine whether special measures are needed to optimize stent deployment such as the use of cutting ballons, rotablators, or balloon inflation using repeated high pressure (Im et al 2015).

In the first patient, coronary angiography showed a lesion of a size quite long from proximal to mid LAD with a size of about $30 \mathrm{~mm}$ with a significant stenosis of $80 \%$. These fairly long-sized lesions also involved a diagonal branch 1 of the LAD so that this type of lesion was also categorized as a bifurcation lesion. Therefore, IVUS can be indicated for use in the first patient.

\section{Role of IVUS in PCI procedure}

Pre-intervention

In pre-intervention period, IVUS can be used to help determine the hemodynamic significance of stenotic coronary arteries, to analyze the anatomy of coronary arteries and stenotic tissue around their walls, and to help choosing the device to be used in PCI procedure by measuring precisely the diameter of the reference artery segment so that the size and type of balloons and stents used will also be appropriate (Kovarnik \& Horak 2012).

Using IVUS we obtained a cross-sectional image of a coronary artery. Tunica intima is a thin layer and only consists of endothelial cells with little connective tissue. Tunica media is sonolucent. Because of the thinness of the tunica intima and the sonolucent nature of the tunica media, these two tunics will appear to be one without a membrane. In the outer layer of the tunica media there is a separating membrane with the tunica adventitia called the external elastic membrane (EEM). If an atherosclerotic plaque is found, the picture will appear on the tunica intima-media. Fat, as the main component of atherosclerotic plaque, has hypoechoic properties with fibrous cap which is also echogenic. If this plaque is calcified, it gives a prominent echogenic image because calcium will inhibit the penetration of ultrasound signals and produce an acoustic shadowing (Nissen \& Yock 2001).

Quantitative measurement of atherosclerotic lesions was performed by measuring plaque burden (PB) by measuring planimetry [(EEM diameter - EUM diameter)/EEM diameter]. However, it should be noted here that $\mathrm{PB}$ values are not equivalent to the percentage of stenosis based on coronary angiography because the percentage of stenosis with coronary angiography is in comparison with the normal segment of the referent artery. This atherosclerotic plaque also needs to be evaluated whether it extends circumferentially to 3600 or longitudinally without any normal segments so that it can be classified into diffuse lesion (Nissen \& Yock 2001).

In the first patient we obtained a mixed lesion. At the beginning of the lesion, an echolucent image of plaques with thin, echogenic fibromuscular lesions appears. However, in the middle to the end of the lesion a fluorescent image was obtained which illustrated the calcification. We obtained PB of $45 \%$ at the beginning of the lesion, and $20-30 \%$ at the middle and end of the lesion. This plaque image also did not extend 
circumferentially, but coronary angiography had a length of about $30 \mathrm{~mm}$ so that we could classify it as a long lesion without diffuse one. Because with coronary angiography we obtained a fairly long lesion of $>20 \mathrm{~mm}$ $(30 \mathrm{~mm})$ in size and with IVUS we found a mixed plaque with PB that nearly 50\% clogged the arterial lumen, and with a high risk of plaque rupture, in the first patient the procedure was continued with stenting.

\section{During the intervention}

During the intervention period, IVUS is useful for lesion preparation. For example, IVUS helps the selection of instruments used during PCI that have been adapted to the anatomy of the lesion, including guidewire, and helps its deployment during PCI process, selecting the size and type of balloons, and choosing the appropriate size and type of the stent. Pre-dilatation using a balloon before stenting is an important phase in the PCI procedure. With balloon dilatation, the coronary artery lumen is expected to widen. One of the most widely used formulas for choosing pre-dilated balloon sizes via IVUS is (EEMrefprox + EEMrefdist)/2, or we can also use measurements from EEMrefdist only. Based on various studies on the use of IVUS, experts argue that the use of a larger balloon size (balloon/arterial ratio of more than 1 based on coronary angiography) is quite safe without increasing the risk of severe acute complications (Kovarnik \& Horak 2012).

In stenting, IVUS can help determine the size of the stent according to the anatomy and morphology of the coronary arteries. This aims to prevent the occurrence of an in-stent restenosis (ISR) complication. ISR is quite common in the types of bare metal stents (BMS), especially if the installation is not optimal. Currently the type of drug eluting stent (DES) has been widely used in PCI procedures because it is significantly able to reduce the risk of ISR. This is because DES-type stent contains kinetic polymer fibers and drug-containing layers (Rogacka et al 2009). However, DES failures are still quite common, comprising $5-10 \%$ of the total population deployed with DES. One of the causes of failure of DES deployment is suboptimal placement. The existence of free struts is believed to play a role in the process of thrombogenesis which results in the formation of stent thrombosis resulting in the acute failure of DES stent deployment (Rogacka et al 2009). DES failure can also occur some time after deployment. Some mechanisms that are thought to cause late DES failure include remodeling arteries that are positive, dissolution of plaque and thrombus behind the stent, and chronic recoiling of the stent, all of which cause the deployment of the stent becomes imperfect, resulting in stent failure (Rogacka et al 2009). Therefore, IVUS still has a place to be used for the deployment, both BMS and DES, because it can optimize the outcome of stent deployment, even though IVUS does not significantly prove capable of reducing the worsening of cardiovascular events within 2 years of stenting (Kovarnik \& Horak 2012, Waksman et al 2013).

In the patient, a pre-dilatation procedure is needed to obtain a wider arterial lumen size by compression or redistribution of plaque. Pre-dilatation also aimed to ensure adequate contact between the stent to be attached to the artery wall. By measuring the EEM in the reference artery, both proximal and distal to the lesion, the recommended balloon size was $3.0 \mathrm{~mm}$. However, given the minimum values of the lumen diameter (MLD) in the referent and distal veins of the lesion were $3.4 \mathrm{~mm}$ and $3.2 \mathrm{~mm}$, this procedure used a pre-dilated balloon with a size of $3.5 \mathrm{~mm}$. Balloon dilatation was performed until it reached a pressure of $10 \mathrm{~atm}$ in distal lesion, and $15 \mathrm{~atm}$ in the proximal part. Then, based on coronary angiography after pre-dilatation, stenting with a size of $3.0 \times 30 \mathrm{~mm}$ was decided to be performed with stent dilatation to a pressure of $14 \mathrm{~atm}$. At this time, the stent had a diameter of $3.25 \mathrm{~mm}$ which corresponded to the diameter of the referent coronary artery. Then, to ensure good and optimal apposition and deployment, post-dilatation was carried out to a pressure of $10 \mathrm{~atm}$ distal to the stent, and $15 \mathrm{~atm}$ proximal to the stent.

\section{Post-intervention}

In post-intervention period, IVUS plays an important role to evaluate whether the stent has been optimally installed or not and to find out whether there are complications after stenting. The optimal criteria for stenting consists of complete apposition and well expansion. Complete apposition describes the presence of a fairly good and perfect contact between the stent "fiber" and the coronary artery wall. Stent expansion describes the ratio between the minimum stent area (MSA) and the lumen area of the referent coronary artery. Stent expansion is regarded as optimal if the MSA obtained is 5.0-5.5 mm2 on non-LM and 6.5-8.7 $\mathrm{mm} 2$ on LM or if the MSA obtained is $>80 \%$ of the mean area of the referent coronary artery in distal and proximal areas with an average risk of complications in the form of ISR around 11-22\%. Apposition that is not good enough can be overcome by post-dilatation using a larger balloon size with low pressure (Yoon \& Hur 2012, Kovarnik \& Horak 2012). Complications of stenting that can be evaluated through IVUS include the presence of an image of haziness that can describe the presence of a coronary artery dissection, plaque residuals, to protrusion from plaque (Kovarnik \& Horak 2012). 


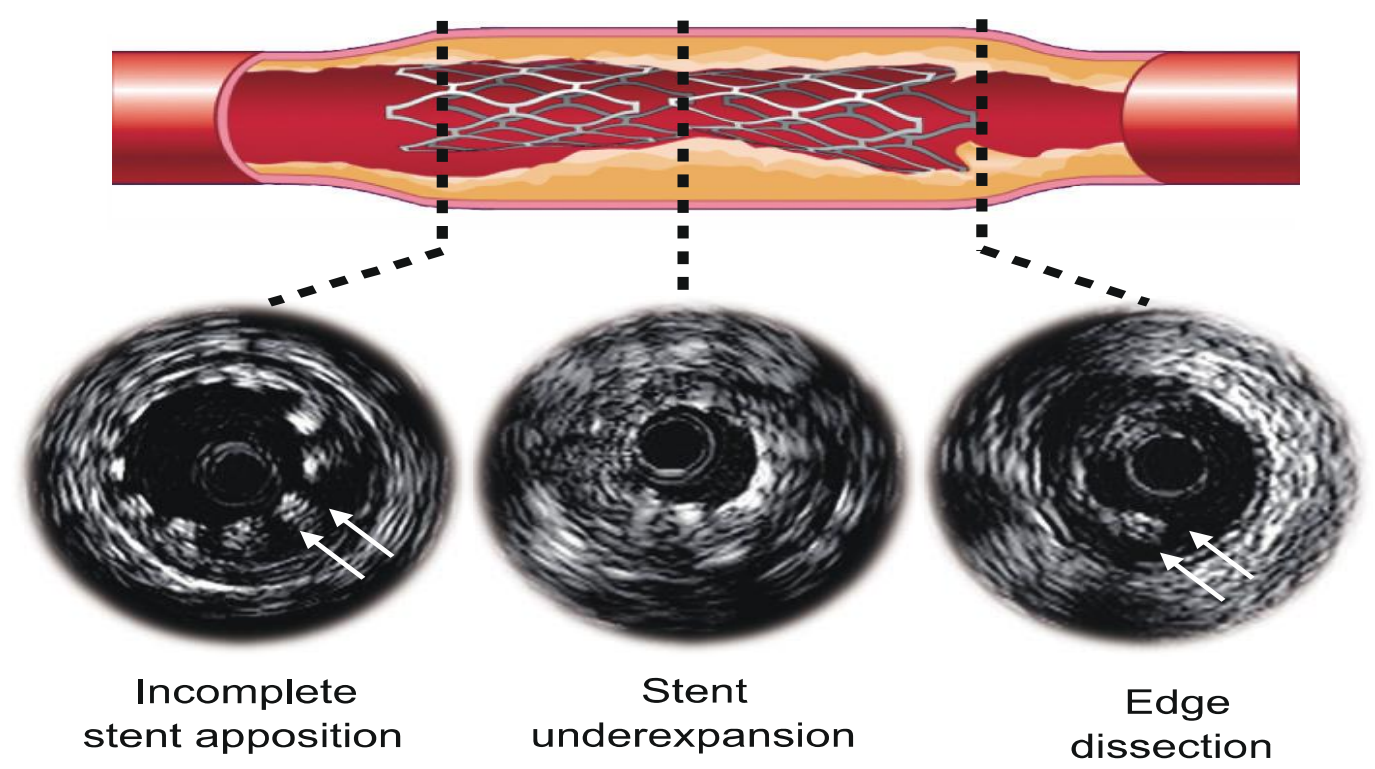

Fig. 10. Complications after stenting (Yoon \& Hur 2012)

Table 1. Guidelines for IVUS recommendations on PCI (Lotfi et al 2013)

\footnotetext{
5.4.2 IVUS: Recommendations

CLASS Ila

1.IVUS is reasonable for the assessment of angiographically indeterminant left main CAD. (Level of Evidence: B)

2. IVUS and coronary angiography are reasonable 4 to 6 weeks and 1 year after cardiac transplantation to exclude donor CAD, detect rapidly progressive cardiac allograft vasculopathy, anc provide prognostic information. (Level of Evidence: $B$ )

3. IVUS is reasonable to determine the mechanism of stent restenosis. (Level of Evidence:C)

CLASS IIb

1. IVUS may be reasonable for the assessment of non-left main coronary arteries with angiographically intermediate coronary stenosis ( $50 \%$ to $70 \%$ diameter stenosis). (Level of Evidence:

2. IVUS may be considered for guidance of coronary stent implantation, particularly in cases of left main coronary artery stenting. (Level of Evidence: B)

3. IVUS may be reasonable to determine the mechanism of stent thrombosis. (Level of Evidence: $C$ )

CLASS III: NO BENEFIT

1.IVUS for routine lesion assessment is not recommended when revascularization with $\mathrm{PCl}$ orCABG is not being contemplated, (Level of Evidence: C)
} 
In the second patient, the stent was deployed with a good apposition, but stent underexpansion was still obtained especially in the area of proximal lesion. The "fiber" of the stent appeared to have good contact with the coronary artery wall. However, MSA was found to be less than $80 \%$ compared to the average lumen area of the proximal and distal referent coronary arteries. Because there was an underexpansion stent, postdilatation was necessary so that no stent installation failed. Post-dilatation was done with balloons larger than stent's size, which was $3.5 \mathrm{~mm}$. The dilatation was done up to a pressure of $10 \mathrm{~atm}$ in the distal part and 20 atm in the proximal part of the lesion. After postdilatation was done, the stent apposition became complete and the expansion became optimal.

Because of its ability to provide a reasonably good visual appearance of the intraluminal and transmural cross-section of coronary arteries during PCI implementation, in 2011 ACC/AHA has provided recommendations for using IVUS in several clinical situations according to Table 1 (Lotfi et al 2013).

\section{CONCLUSION}

IVUS is one of the supporting examinations that has an important role in PCI procedure. Identification of the cross-section of the coronary artery lumen affected by the lesion will help optimize the installation of stents, so as to reduce the incidence of ISR, stent thrombosis, or other complications, which will ultimately increase the success rate of PCI procedure. However, it turns out that there are no uniform IVUS criteria regarding optimal stent deployment and routine use of IVUS in PCI procedure is not recommended, except for intermediate coronary artery lesions and/or lesions in LM.

We have reported two cases, the first being a male patient, aged 43 years, with a diagnosis of post-stent TVD (Triple Vessel Disease) in RCA with risk factors of hypertension, diabetes mellitus, and smoking. We decided to do an examination and evaluation using IVUS before the stent deployment procedure was performed. The second patient was a male, 46 years old with a diagnosis of post-stent CHD DVD (Double Vessel Disease) in RCA with risk factors of dyslipidemia and smoking. We decided to do an evaluation with IVUS after the stent deployment procedure was performed. The final result was obtained either by optimal stent deployment (with well appo- sition and good deployment). Residual stenosis after stenting was not found.

\section{REFERENCES}

Boudi B (2015). Coronary artery atherosclerosis. Available from: http://emedicine.medscape.com/article/153647. Accessed March 12, 2016

Dharma S, Juzar DA, Firdaus I, Soerianata, Wardeh AJ, Jukema JW (2012). Acute myocardial infarction system of care in the third world. Neth Heart J 20, 254-259

Im E, Kim JS, Hong MK (2015). Intravascular ultrasound as an adjunct tool for angiographycally intermediate lesions and complex coronary interventions: patient selection and perspective. Vasc J Diag 3, 41-51

Kovarnik T, Horak J (2012). IVUS Guided PCI. In: Honda Y, editor. Intravascular ultrasound. InTech

Lin CP, Honye J, Chang CJ, Kuo CT (2011). Clinical application of intravascular ultrasound in coronary artery disease: an update. Acta Cardiol Sin 27, 1-3

Liu X, Doi H, Maehara A, Mintz GS, Ribamar J, Sano K, Weisz G, Dangas GD, Lansky AJ, Kreps EM, Collins M, Fahy M, Stone GW, Moses JW, Leon MB, Mehran R (2009). A volumetric intravascular ultrasound comparison of early drug-eluting stent thrombosis versus restenosis. J Am Coll Cardiol Intv $2,428-34$

Lotfi A, Jeremias A, Fearon WF, Feldman MD, Mehran R, Messenger JC, Grines CL, Dean LS, Kern MJ, Klein LW (2013). Expert consensus statement on the use of fractional flow reserve, intravascular ultrasound, and optical coherence tomography: A consensus statement of the society of cardiovascular angiography and interventions. Catheter Cardiovasc Interv 29, 741-752

Nissen SE, Yock P (2001). Intravascular ultrasound novel pathophysiological insights and current clinical applications. Circulation 103, 604-616

Rogacka R, Latib A, Colombo A (2009). IVUS-guided stent implantation to improve outcome: a promise waiting to be fulfilled. Current Cardiology Review 5, 78-86

Waksman R, Kitabata H, Prati F, Albertucci M, Mintz GS (2013). Intravascular ultrasound versus optical coherence tomography guidance. Am J Cardiol 62, 3240

Yoon HJ, Hur SH (2012). Optimization of stent deployment by intravascular ultrasound. Korean $\mathbf{J}$ Intern Med 27, 30-38 